\title{
Relationship of clinical symptoms with biomarkers of inflammation in pediatric inflammatory bowel disease
}

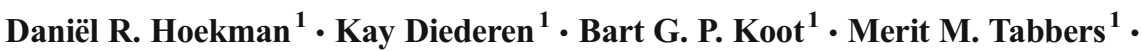 \\ Angelika Kindermann ${ }^{1} \cdot$ Marc A. Benninga ${ }^{1}$
}

Received: 8 June 2016 /Revised: 3 August 2016 / Accepted: 15 August 2016 / Published online: 29 August 2016

(C) The Author(s) 2016. This article is published with open access at Springerlink.com

\begin{abstract}
In adult inflammatory bowel disease (IBD) patients, there is a strong discrepancy between symptoms and biomarkers of inflammation. Data on pediatric IBD patients are conflicting. Therefore, we aimed to investigate the relationship between clinical symptoms and biomarkers of inflammation in pediatric IBD. Patients aged $<18$ years with previously diagnosed Crohn's disease (CD) or ulcerative colitis (UC) were included. Clinical disease activity was determined using the abbreviated Pediatric CD Activity Index (aPCDAI) or Pediatric UC
\end{abstract}

Daniël R. Hoekman and Kay Diederen contributed equally to this work.

Communicated by Peter de Winter

Electronic supplementary material The online version of this article (doi:10.1007/s00431-016-2762-2) contains supplementary material, which is available to authorized users.

Marc A. Benninga

m.a.benninga@amc.uva.nl

Daniël R. Hoekman

d.r.hoekman@amc.uva.nl

Kay Diederen

k.diederen@amc.uva.nl

Bart G. P. Koot

b.g.koot@amc.uva.nl

Merit M. Tabbers

m.m.tabbers@amc.uva.nl

Angelika Kindermann

a.kindermann@amc.uva.nl

1 Department of Pediatric Gastroenterology and Nutrition, Academic Medical Center, Meibergdreef 9, 1105

AZ Amsterdam, The Netherlands
Activity Index (PUCAI). Biochemical disease activity was assessed using fecal calprotectin (FC) and Creactive protein (CRP). In total, 127 patients (62 male; median age 14.9 years) were included ( $82 \mathrm{CD}, 45 \mathrm{UC}$ ). FC correlated weakly with total aPCDAI score $\left(r_{\mathrm{s}}=0.32\right.$; $95 \%$ CI $0.12-0.51 ; p=0.003)$ and total PUCAI score $\left(r_{\mathrm{s}}=0.36 ; 95 \%\right.$ CI $\left.0.07-0.62 ; p=0.015\right)$. Only aPCDAI components abdominal examination and perirectal disease and PUCAI component activity level had a significant correlation with levels of FC. CRP correlated weakly with total aPCDAI score $\left(r_{\mathrm{s}}=0.28 ; 95 \%\right.$ CI $0.05-0.46$; $p=0.012)$ and aPCDAI components abdominal examination and activity level. No significant correlation was observed between CRP and total PUCAI score $\left(r_{\mathrm{s}}=0.01\right.$; $95 \%$ CI $-0.34-0.29 ; p=0.961)$ or individual PUCAI components.

Conclusion: There is a strong discrepancy between clinical symptoms and biomarkers of inflammation in children with IBD.

What is Known:

- A substantial proportion of asymptomatic pediatric inflammatory bowel disease (IBD) patients have elevated biomarkers of inflammation.

- There is a strong discrepancy between symptoms and biomarkers of inflammation in adults with IBD.

What is New:

- Clinical symptoms are only weakly associated with levels of fecal calprotectin and serum C-reactive protein in children and adolescents with previously diagnosed IBD.

- Similarly to adult IBD patients, there is a strong discrepancy between clinical symptoms and biomarkers of inflammation in children with IBD.

Keywords Crohn's disease $\cdot$ Ulcerative colitis $\cdot$ Inflammatory bowel disease $\cdot$ Disease activity $\cdot$ Fecal calprotectin 


$\begin{array}{ll}\begin{array}{l}\text { Abbreviations } \\ \text { aPCDAI }\end{array} & \begin{array}{l}\text { Abbreviated Pediatric Crohn's Disease Activity } \\ \text { Index }\end{array} \\ \text { CD } & \text { Crohn's disease } \\ \text { CRP } & \text { C-reactive protein } \\ \text { FC } & \text { Fecal calprotectin } \\ \text { PUCAI } & \text { Pediatric Ulcerative Colitis Activity Index } \\ \text { UC } & \text { Ulcerative colitis }\end{array}$

\section{Introduction}

Traditionally, treatment of inflammatory bowel disease (IBD) was mainly guided by symptoms such as abdominal pain, bowel habits, and general well-being. Symptomatic treatment, however, may not improve long-term outcome or slow disease progression [27], possibly because symptoms may not accurately reflect the underlying inflammatory process [19]. Therefore, mucosal healing (often defined as the complete resolution of macroscopic inflammation on endoscopy) is increasingly advocated as a therapeutic target in IBD [27]. Indeed, mucosal healing is a predictor of long-term outcome of both Crohn's disease (CD) and ulcerative colitis (UC) [31, 32]. However, due to its invasiveness and costs, endoscopy is not ideal for frequent monitoring of disease activity. Therefore, in current practice, biomarkers such as fecal calprotectin (FC) and serum C-reactive protein (CRP) are frequently used as surrogate markers of endoscopic IBD activity. Especially, levels of FC have a strong correlation with endoscopic disease activity $[26,7,6,36]$. It can, however, be argued that complete normalization of FC - potentially indicating complete resolution of macroscopic and microscopic inflammation - is a therapeutic target beyond mucosal healing. In support of this, recent studies in adults have shown that even in the absence of endoscopic signs of disease activity, levels of FC are predictive of long-term outcome [28, 20]. Furthermore, a therapeutic algorithm based on levels of FC alone did improve medium-term outcome in adults with IBD $[24,26]$. However, the optimal target of treating IBD remains to be established, and a gold standard for monitoring IBD is currently not available [26].

A substantial proportion of asymptomatic pediatric IBD patients have elevated biomarkers of inflammation [35]. Data on adult IBD patients indeed indicate that there is a strong discrepancy between clinical symptoms and biochemical markers of inflammation [3, 36]. Data on pediatric IBD are conflicting, with reported correlations between symptoms and FC levels ranging from absent $(r=0.0)[12,33]$ to strong $(r=0.7)$ [13] in CD and from weak $(r=0.3)$ [15] to strong $(r=0.8)$ [2] in UC.

We aimed to investigate the relationship of clinical symptoms with biochemical markers of inflammation in a random sample of children and adolescents who were previously diagnosed with and treated for IBD.

\section{Methods}

\section{Patients}

In this cross-sectional, observational study, we aimed to include children and adolescents (aged $<18$ years) with an established diagnosis of CD or UC according to revised Porto criteria [17], who visited the outpatient pediatric gastroenterology clinic of the Emma Children's Hospital/Academic Medical Center, Amsterdam, the Netherlands. Patients with IBDU, an ileo- or colostomy, or a colectomy with ileal pouch-anal anastomosis were excluded. Approval from the local Medical Ethics Review Committee was obtained.

\section{Data collection}

Patient characteristics were obtained from patients' medical records, including age, sex, age at diagnosis, disease duration, disease location and behavior, the presence of (previous) growth impairment, current medication, and previous IBDrelated surgery. Paris classification was used to classify IBD phenotype [16].

Clinical disease activity was determined using the Pediatric Ulcerative Colitis Activity Index (PUCAI) for UC patients [37] or the abbreviated Pediatric Crohn's Disease Activity Index (aPCDAI) for CD patients (Online Resource) [18, 34]. The PUCAI consists of six clinical items, with scores ranging from 0 to 85 , with cutoff scores for remission ( $<10$ points), mild (10-34), moderate (35-64), and severe disease $(\geq 65)$ [37]. The aPCDAI consists of six clinical items, with scores ranging from 0 to 70 , with cutoff scores for remission $(<10$ points), mild (10-25), moderate (26-39), and severe disease $(\geq 40)[34,18]$.

Biochemical disease activity was assessed using FC and serum CRP levels at the time of assessing clinical disease activity. Fecal calprotectin concentrations were measured using an enzyme-linked immunosorbent assay (Bühlmann Laboratories, Switzerland). The respective lower and upper limits of detection were 0 and $1800 \mu \mathrm{g} / \mathrm{g}$. For the assessment of biochemical remission, previously suggested cutoff levels of $<250 \mu \mathrm{g} / \mathrm{g}$ [7] for FC and $<5 \mathrm{mg} / \mathrm{L}$ [21] for CRP were used (FC-based remission and CRP-based remission, respectively). For exploratory analyses, different FC cutoff levels of $<50 \mu \mathrm{g} / \mathrm{g}$ [21] and $<1000 \mu \mathrm{g} / \mathrm{g}$ were used.

\section{Sample size}

Sample size calculation was based on the power to detect a correlation coefficient that we considered clinically 
meaningful ( $r \geq 0.5$, resulting in an explained variance $\geq 25 \%$ ). A two-sided Fisher's $z$ test with an alpha of 0.05 will have $90 \%$ power to detect a Pearson's correlation coefficient of 0.5 when the sample size is 38 . Accounting for nonparametric testing (15\%), we aimed to include at least 44 $\mathrm{CD}$ patients and $44 \mathrm{UC}$ patients.

\section{Statistical analysis}

Primary analysis was the correlation between levels of FC and clinical indices. Secondary analyses included the correlation between levels of CRP and clinical indices and the correlation of both biomarkers with individual components of disease activity indices. Continuous data with a non-normal distribution were reported using medians and interquartile ranges (IQR). Mann-Whitney $U$ tests were used to compare differences between groups, and Spearman's rank correlations were used to investigate the relation between two parameters with $95 \%$ confidence intervals (CIs) based on bootstrapping with 1000 samples with the same size as the original sample with replacement. The null hypothesis (no correlation between clinical symptoms and biochemical markers of inflammation) was rejected if the $95 \%$ CI of the Spearman's rank coefficient $\left(r_{\mathrm{s}}\right)$ did not include 0 . Categorical/dichotomous data were reported as percentages, and Fisher's exact tests were used to compare differences between groups. Point-biserial correlations were used to investigate the relation between continuous and dichotomous outcomes. Significance was set at $p<0.05$. Statistical analysis was performed using IBM SPSS Statistics 22 for Windows.

\section{Results}

\section{Patient characteristics}

Between March 2014 and March 2016, a total of 127 patients (49\% male) with a median age of 14.9 years (IQR 13.5-16.4) were included, 82 with a diagnosis of $\mathrm{CD}$ and 45 with a diagnosis of UC (Table 1). Based on clinical indices, 79 (63\%) patients were in remission (CD 54 [66\%]; CU 25 [56\%]), 42 (33\%) patients had mild disease activity (CD 27 [33]\%; UC $15[33 \%]$ ), and $6(5 \%)$ patients had moderate disease activity (CD 1 [1\%]; UC 5 [11\%]). No patients had severe disease activity at the time of evaluation.

In total, 48 (38\%) patients were in FC-based remission, of whom $13(27 \%)$ had clinically active disease. An overview of these patients' symptoms is provided in the Online Resource.

\section{Biochemical markers in Crohn's disease}

\section{Fecal calprotectin}

The median FC level in patients with CD was $260 \mu \mathrm{g} / \mathrm{g}$ (IQR 76-1297; range $1-1800 \mu \mathrm{g} / \mathrm{g}$ ). The proportion of patients with $\mathrm{CD}$ in FC-based remission was $50 \%$. The proportion of patients with $\mathrm{CD}$ in clinical remission with FC-based remission was highly dependent on the cutoff for biochemical remission and was higher compared to patients with clinically active disease (Table 2). Fecal calprotectin had a weak but significant positive correlation with the total aPCDAI score $\left(r_{\mathrm{s}}=0.32\right.$ [95\% CI 0.13-0.49]; $p=0.003$; Fig. 1a). Furthermore, FC levels had a weak positive correlation with the aPCDAI components abdominal examination $\left(r_{\mathrm{s}}=0.23\right.$ [95\% CI 0.02-0.40]; $p=0.037)$ and perirectal disease $\left(r_{\mathrm{s}}=0.23\right.$ [95\% CI $\left.0.10-0.34\right]$; $p=0.036$; Table 3).

\section{C-reactive protein}

The median CRP level in patients with CD was $1.3 \mathrm{mg} / \mathrm{L}$ (IQR $0.4-5.0$; range $0.3-44.0 \mathrm{mg} / \mathrm{L}$ ). The proportion of CD patients in CRP-based remission determined with CRP was $73 \%$. Crohn's disease patients in clinical remission were more frequently in CRP-based remission, compared to patients with active disease (Table 2). C-reactive protein had a weak positive correlation with the total aPCDAI score $\left(r_{\mathrm{s}}=0.28\right.$ [95\% CI $\left.0.05-0.46\right]$; $p=0.012$; Fig. 1b). Furthermore, CRP levels had a weak positive correlation with the aPCDAI components abdominal examination $\left(r_{\mathrm{s}}=0.33\right.$ [95 \% CI $0.14-0.48$; $p=0.003)$ and patient functioning $\left(r_{\mathrm{s}}=0.24[95 \% \mathrm{CI}\right.$ $0.01-0.45 ; p=0.028$; Table 3 ). In CD patients, CRP levels had a moderate positive correlation with FC levels $\left(r_{\mathrm{s}}=0.459\right.$ [95\% CI 0.27-0.62]; $\left.p<0.001\right)$.

\section{Biochemical markers in ulcerative colitis}

\section{Fecal calprotectin}

The median FC level in patients with UC was $398 \mu \mathrm{g} / \mathrm{g}$ (IQR 73-1290; range 1-1800 $\mu \mathrm{g} / \mathrm{g}$ ). The proportion of patients with UC in FC-based remission was $40 \%$. Similar to the analysis in $\mathrm{CD}$, the proportion of patients with $\mathrm{UC}$ in clinical remission with FC-based remission was highly dependent on the cutoff for biochemical remission. However, no significant difference was found in biochemical remission rate between patients with and without clinically active disease (Table 2). Fecal calprotectin had a weak positive correlation with the total PUCAI score $\left(r_{\mathrm{s}}=0.36\right.$ [95\% CI 0.07-0.61]; $p=0.015$; Fig. 2a and Table 3). Furthermore, the activity level component of the PUCAI had a moderate positive correlation with 
Table 1 Patient characteristics

\begin{tabular}{|c|c|c|}
\hline & $\mathrm{CD}(n=82)$ & $\mathrm{UC}(n=45)$ \\
\hline Age (median, IQR) & $15.0(13.1-16.6)$ & $14.2(11.4-16.7)$ \\
\hline Males $(n, \%)$ & $43(52 \%)$ & $19(42 \%)$ \\
\hline Months since diagnosis of IBD (median, IQR) & $26.1(9.8-39.1)$ & $22.4(7.6-43.6)$ \\
\hline Current medication for IBD $(n, \%)$ & $77(93 \%)$ & $43(96 \%)$ \\
\hline - Anti-TNF $(n, \%)$ & $32(39 \%)$ & $2(4 \%)$ \\
\hline - Steroids $(n, \%)$ & $7(9 \%)$ & $9(20 \%)$ \\
\hline - Thiopurine $(n, \%)$ & $36(44 \%)$ & $16(36 \%)$ \\
\hline - Methotrexate $(n, \%)$ & $8(10 \%)$ & $0(0 \%)$ \\
\hline$\cdot 5$-ASA $(n, \%)$ & $9(11 \%)$ & $37(82 \%)$ \\
\hline Previous IBD-related surgery $(n, \%)$ & $12(15 \%)$ & $1(2 \%)$ \\
\hline - Perianal surgery $(n, \%)$ & $7(8 \%)$ & $0(0 \%)$ \\
\hline - Resectional surgery $(n, \%)$ & $5(6 \%)$ & $1(2 \%)$ \\
\hline \multicolumn{3}{|l|}{ CD: age at diagnosis (Paris classification) } \\
\hline - A1a $0<10$ years $(n, \%)$ & $25(30 \%)$ & \\
\hline - A1b $10<17$ years $(n, \%)$ & $57(70 \%)$ & \\
\hline - A2 17-40 years $(n, \%)$ & $0(0 \%)$ & \\
\hline \multicolumn{3}{|l|}{ CD: location ${ }^{\mathrm{a}}$ (Paris classification) } \\
\hline - $\mathrm{L} 1(n, \%)$ & $7(9 \%)$ & \\
\hline - L2 $(n, \%)$ & $24(29 \%)$ & \\
\hline - L3 $(n, \%)$ & $49(60 \%)$ & \\
\hline - L4a $(n, \%)$ & $34(41 \%)$ & \\
\hline - L4b $(n, \%)$ & $3(4 \%)$ & \\
\hline - L4ab $(n, \%)$ & $1(1 \%)$ & \\
\hline \multicolumn{3}{|l|}{ CD: behavior (Paris classification) } \\
\hline - B1 non-structuring, non-penetrating $(n, \%)$ & $69(84 \%)$ & \\
\hline • B2 structuring $(n, \%)$ & $7(9 \%)$ & \\
\hline - B3 penetrating $(n, \%)$ & $5(6 \%)$ & \\
\hline - B2B3 penetrating and structuring $(n, \%)$ & $1(1 \%)$ & \\
\hline - $p$ perianal disease $(n, \%)$ & $13(16 \%)$ & \\
\hline \multicolumn{3}{|l|}{ CD: growth impairment (Paris classification) } \\
\hline - Evidence of growth delay $(n, \%)$ & $14(17 \%)$ & \\
\hline CD: aPCDAI (median, IQR) & $5(0-10)$ & \\
\hline \multicolumn{3}{|l|}{ UC: extent (Paris classification) } \\
\hline - E1 proctitis $(n, \%)$ & & $5(11 \%)$ \\
\hline - E2 left-sided disease $(n, \%)$ & & $11(24 \%)$ \\
\hline - E3 extensive disease $(n, \%)$ & & $6(13 \%)$ \\
\hline • E4 pancolitis $(n, \%)$ & & $23(51 \%)$ \\
\hline \multicolumn{3}{|l|}{ UC: severity ${ }^{\mathrm{b}}$ (Paris classification) } \\
\hline - $\mathrm{S} 1$ ever severe $(n, \%)$ & & $9(20 \%)$ \\
\hline UC: PUCAI (median, IQR) & & $5(0-15)$ \\
\hline
\end{tabular}

aPCDAI abbreviated Pediatric Crohn's Disease Activity Index, $C D$ Crohn's disease, PUCAI Pediatric Ulcerative Colitis Activity Index, $U C$ ulcerative colitis

${ }^{\text {a }} \mathrm{L} 1$ distal 1/3 ileum \pm limited cecal disease, $\mathrm{L} 2$ colonic, $\mathrm{L} 3$ ileocolonic, L4a upper disease proximal to ligament of Treitz, L4b upper disease distal to ligament of Treitz and proximal to distal $1 / 3$ ileum

${ }^{\mathrm{b}}$ Defined as ever a $\mathrm{PUCAI} \geq 65$ points

levels of $\mathrm{FC}\left(r_{\mathrm{s}}=0.46[95 \%\right.$ CI $0.20-0.68] ; p=0.001$; Table 3).

\section{C-reactive protein}

The median CRP level in patients with UC was $1.5 \mathrm{mg} / \mathrm{L}$ (IQR $0.5-4.2$; range $0.1-22.2 \mathrm{mg} / \mathrm{L}$ ). The proportion of UC patients in CRP-based remission was $78 \%$. There was no difference in the proportion of patients in CRPbased remission, in patients with or without clinically active UC (Table 2). No significant correlation was observed between the total PUCAI score $\left(r_{\mathrm{s}} 0.01[95 \% \mathrm{CI}\right.$ $-0.34-0.30] ; p=0.961)$ or individual PUCAI components and CRP levels (Fig. 2b and Table 3). In UC patients, CRP levels showed no significant correlation with FC levels $\left(r_{\mathrm{s}}=0.09\right.$ [95\% CI $\left.\left.-0.21-0.39\right] ; p=0.542\right)$.

\section{Discussion}

In this study, we evaluated the relationship of biomarkers of disease activity with clinical symptoms in children and adolescents who were previously diagnosed with IBD. In both $\mathrm{CD}$ and UC patients, the total disease activity index score had a weak positive correlation with FC levels. Only the aPCDAI components abdominal examination and perirectal 
Table 2 The distribution of biochemical disease activity in clinical remission or active disease

\begin{tabular}{llll}
\hline $\mathrm{CD}$ & Clinical remission $^{\mathrm{a}}(n=54)$ & Active disease $^{\mathrm{b}}(n=28)$ & $p$ value \\
$\mathrm{FC}<50 \mu \mathrm{g} / \mathrm{g}$ & $15(28 \%)$ & $1(4 \%)$ & 0.008 \\
$\mathrm{FC}<250 \mu \mathrm{g} / \mathrm{g}$ & $34(63 \%)$ & $7(25 \%)$ & 0.002 \\
$\mathrm{FC}<1000 \mu \mathrm{g} / \mathrm{g}$ & $43(80 \%)$ & $15(54 \%)$ & 0.021 \\
$\mathrm{CRP}<5 \mathrm{mg} / \mathrm{L}$ & $45(83 \%)$ & $15(54 \%)$ & 0.008 \\
$\mathrm{UC}$ & Clinical remission ${ }^{\mathrm{a}}(n=25)$ & Active disease ${ }^{\mathrm{b}}(n=20)$ & $p$ value \\
$\mathrm{FC}<50 \mu \mathrm{g} / \mathrm{g}$ & $4(16 \%)$ & $2(10 \%)$ & 0.678 \\
$\mathrm{FC}<250 \mu \mathrm{g} / \mathrm{g}$ & $12(48 \%)$ & $6(30 \%)$ & 0.359 \\
$\mathrm{FC}<1000 \mu \mathrm{g} / \mathrm{g}$ & $23(92 \%)$ & $10(50 \%)$ & 0.002 \\
$\mathrm{CRP}<5 \mathrm{mg} / \mathrm{L}$ & $20(80 \%)$ & $15(75 \%)$ & 0.731 \\
\hline
\end{tabular}

$C D$ Crohn's disease, $C R P$ C-reactive protein, $F C$ fecal calprotectin, $U C$ ulcerative colitis

${ }^{a}$ Abbreviated Pediatric Crohn's Disease Activity Index $<10$ or Pediatric Ulcerative Colitis Activity Index $<10$

${ }^{\mathrm{b}}$ Abbreviated Pediatric Crohn's Disease Activity Index $<10$ or Pediatric Ulcerative Colitis Activity Index $<10$ disease and the PUCAI component activity level correlated significantly with FC levels, albeit weakly. In CD patients, CRP had a weak positive correlation with the total aPCDAI score and the aPCDAI components abdominal examination
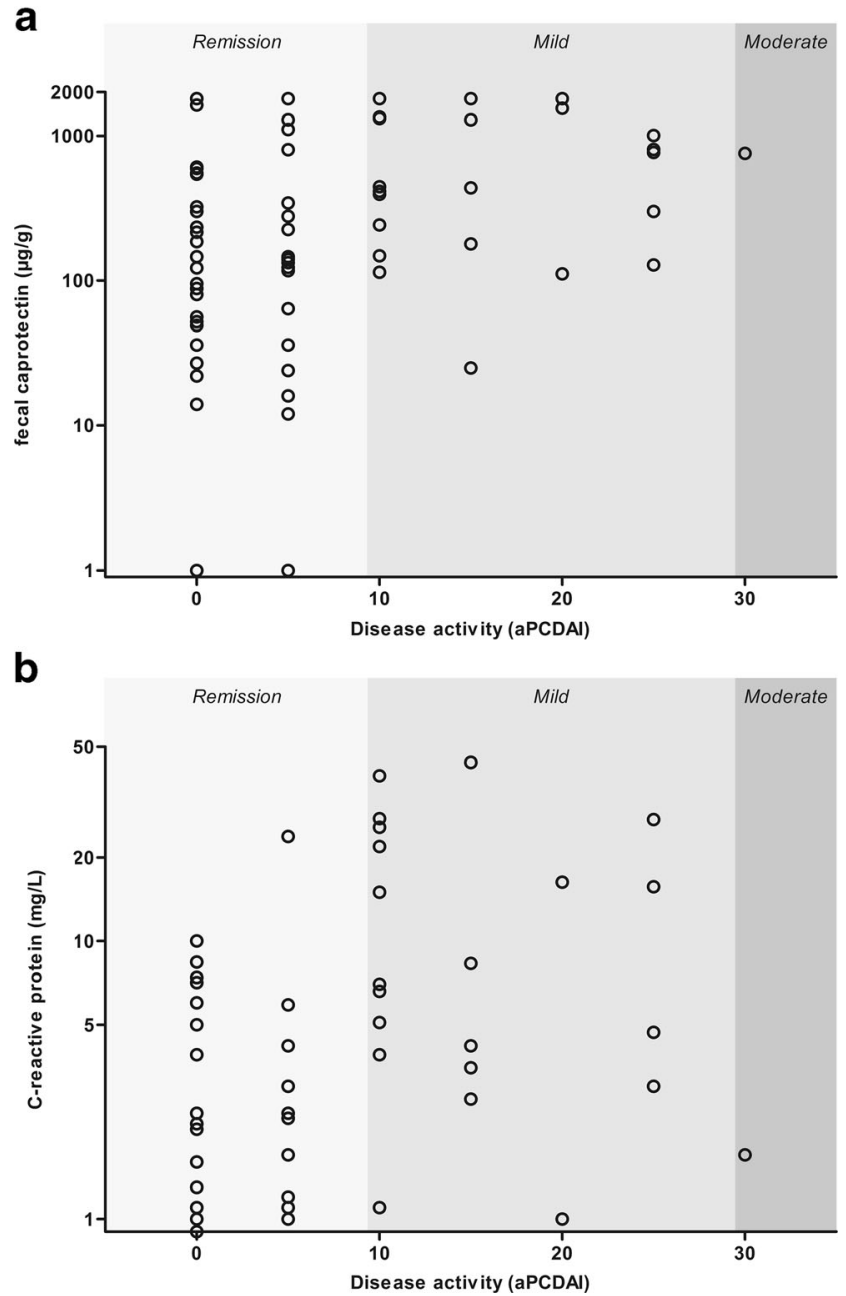

Fig. 1 a Fecal calprotectin and b C-reactive protein levels by clinical disease activity as assessed by aPCDAI and patient functioning. In UC patients, CRP did not correlate with total disease activity index score nor with its individual components.

The correlation between FC levels and the total aPCDAI score in this study is lower than the correlation of FC levels with the original Pediatric Crohn's Disease Activity Index (PCDAI) that is reported in previous studies $[1,9,10,15$, 13], although results have not been unequivocal [4, 33]. This may be related to the fact that the aPCDAI consists only of clinical components, as opposed to the original PCDAI, which also includes laboratory parameters. The exclusion of these additional parameters from the clinical disease activity score may have reduced the correlation with FC levels, since they are known to correlate with FC levels [7]. In this study, we chose to use the aPCDAI because it is a measure of purely clinical disease activity, as opposed to the original PCDAI.

Of the individual aPCDAI components, only abdominal examination and perirectal disease correlated with FC levels. This may be explained by the more objective nature of these observations, compared to the more subjective components such as abdominal pain and patient functioning. However, in studies of adults with $\mathrm{CD}$, no correlation was found between FC levels and perirectal disease [30]. In addition, the more objective component stool consistency of the aPCDAI was not related to levels of FC. Surprisingly, activity level, arguably the most subjective component of the PUCAI, was the only component that correlated significantly with FC level. Similarly, activity level expressed as the level of experienced fatigue was previously found to correlate positively with levels of biochemical disease activity in adult IBD patients [42].

Overall, only a weak correlation was found between clinical disease activity and levels of FC, probably the most sensitive currently available marker for gastrointestinal inflammation in IBD. Even the upper limits of the $95 \%$ CIs of the correlation coefficients ( 0.51 for $\mathrm{CD}$ and 0.62 for $\mathrm{UC}$ ) indicate that, at most, only a small proportion (respectively, 26 and 
Table 3 Correlation between the clinical indices total scores, individual components, and biochemical markers of disease activity

\begin{tabular}{lll}
\hline CD (aPCDAI) & FC $\left(r_{\mathrm{s}}\right)$ & CRP $\left(r_{\mathrm{s}}\right)$ \\
Abdominal pain $^{\mathrm{a}}$ & 0.133 & 0.180 \\
Stools (per day) $^{\mathrm{a}}$ & 0.156 & 0.020 \\
Patient functioning $^{\mathrm{a}}$ & 0.177 & $0.242^{*}$ \\
Weight $^{\mathrm{a}}$ & 0.185 & 0.052 \\
Abdominal examination $^{\mathrm{a}}$ & $0.231^{*}$ & $0.326^{*}$ \\
Perirectal disease $^{\mathrm{a}}$ & $0.232^{*}$ & 0.023 \\
Total aPCDAI score $^{\mathrm{a}}$ & $0.324^{*}$ & $0.275^{*}$ \\
UC (PUCAI) $_{\text {Abdominal pain }^{\mathrm{a}}}$ & $\mathrm{FC}\left(r_{\mathrm{s}}\right)$ & $\mathrm{CRP}\left(r_{\mathrm{s}}\right)$ \\
Rectal bleeding $^{\mathrm{a}}$ & 0.147 & -0.039 \\
Stool consistency of most stools $^{\mathrm{a}}$ & 0.192 & 0.057 \\
${\text { Number of stool per } 24 \mathrm{~h}^{\mathrm{a}}}^{\mathrm{a}}$ & 0.203 & 0.121 \\
Nocturnal stools $_{\quad \text { any episodes causing wakening) }}^{\mathrm{b}}$ & 0.270 & 0.140 \\
Activity level $^{\mathrm{a}}$ & 0.239 & 0.190 \\
Total PUCAI score $^{\mathrm{a}}$ & $0.461^{*}$ & -0.008 \\
\hline
\end{tabular}

aPCDAI abbreviated Pediatric Crohn's Disease Activity Index, $C D$ Crohn's disease, $C R P$ C-reactive protein, $F C$ fecal calprotectin, $P U C A I$ Pediatric Ulcerative Colitis Activity Index, $U C$ ulcerative colitis

*Significant correlation $(p<0.05)$

${ }^{\text {a }}$ Spearman's rank correlations

${ }^{\mathrm{b}}$ Point-biserial correlation

$37 \%$ ) of variation in symptoms can be explained by variation in inflammation. This may partly be explained by the fact that disease activity was relatively mild in our study population. Indeed, the majority of patients were in clinical remission. Consequently, the relatively small variation in the total clinical indices scores potentially decreased the strength of the correlation. However, the distribution of disease activity in our study appears to be similar to that of large cohort studies on the clinical course of pediatric IBD $[22,11]$. Thus, the correlation that we found is more likely to reflect the relationship between symptoms and the degree of intestinal inflammation in daily practice, compared to previously reported correlation coefficients from studies that also included patients at the time of diagnosis $[9,1,4]$.

The lack of correlation between levels of CRP and clinical disease activity in patients with UC can be explained by the poor sensitivity of CRP for endoscopically active UC [29, 25]. The reason why CRP seems to be less accurate in $\mathrm{UC}$ compared to $\mathrm{CD}$ is unclear, although it may be explained by the fact that in UC, inflammation is limited to the mucosa, in contrast to the transmural inflammation in CD [38]. Moreover, serum levels of IL6 , the main mediator of the production of CRP, are shown to be higher in children with CD compared to those with UC [5].
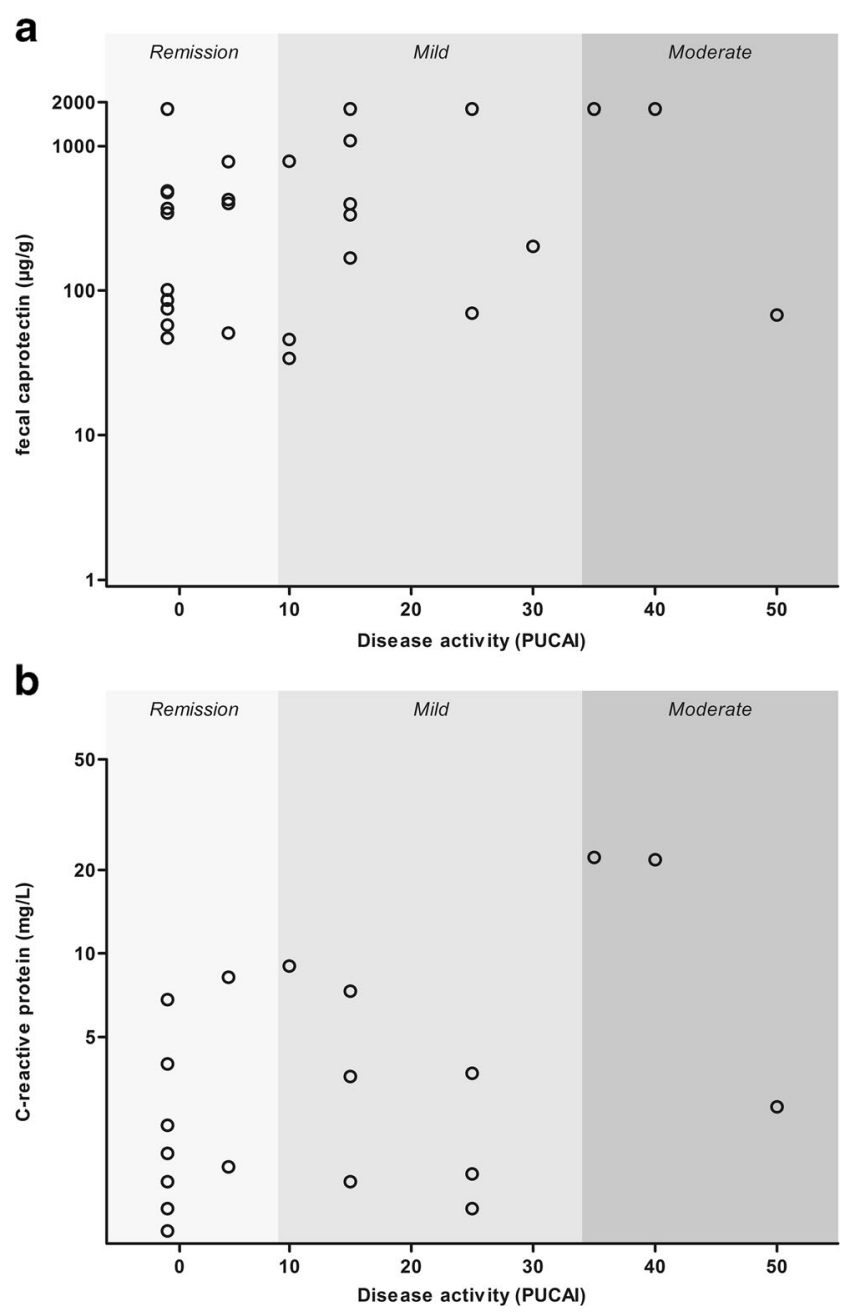

Fig. 2 a Fecal calprotectin and $\mathbf{b}$ C-reactive protein levels by clinical disease activity as assessed by PUCAI

In our study, a large proportion of patients had elevated serum and fecal markers of inflammation, despite the complete absence of clinical symptoms. This may be partly explained by the suboptimal accuracy of these biomarkers. However, in our opinion, these elevated inflammatory markers in patients with quiescent IBD probably reflect ongoing IBD activity in the majority of patients. Indeed, many studies have shown that children and adults with IBD in clinical remission have ongoing inflammation on endoscopy [39, $23,8,14,41,40]$.

The discrepancy between clinical symptoms and biochemical markers of inflammation may have important implications for the management of IBD. Since symptoms are only weakly associated with the underlying inflammatory process, one could argue whether it should be a prerequisite that a therapeutic agent reduces both clinical symptoms and the underlying inflammation. Perhaps these are two distinct aims, potentially with two distinct interventions or treatment strategies. Future research is required to determine the optimal strategy to attain both goals. 
The strength of our study is that we included a random sample of children and adolescents with an established diagnosis of IBD. Consequently, our findings are likely to reflect the relationship between disease activity and the degree of intestinal inflammation in daily practice. A weakness is that we did not assess disease activity using endoscopy with histology, since in our practice, endoscopy is not routinely performed to monitor disease activity during follow-up.

In conclusion, in this study of children with previously diagnosed IBD, clinical disease activity was only weakly associated with inflammatory markers FC and CRP. This may implicate that clinical symptoms and inflammatory markers represent two distinct aspects of disease activity and should be considered separately in clinical decision-making.

Author's contributions $\mathrm{KD}$ and $\mathrm{DH}$ collected and analyzed the data, drafted the initial manuscript, revised the manuscript, and approved the final manuscript as submitted. BK collected the data, revised the manuscript, and approved the final manuscript as submitted. MT collected the data, revised the manuscript, and approved the final manuscript as submitted. AK collected the data, supervised drafting of the manuscript, revised the manuscript, and approved the final manuscript as submitted. MB collected the data, supervised drafting of the manuscript, revised the manuscript, and approved the final manuscript as submitted.

\section{Compliance with ethical standards}

Conflict of interest The authors declare that they have no conflict of interest. No external funding was obtained for the preparation of this manuscript.

Ethical approval All procedures performed in studies involving human participants were in accordance with the ethical standards of the institutional and/or national research committee and with the 1964 Helsinki Declaration and its later amendments or comparable ethical standards.

Informed consent For this type of study, formal consent is not required.

Open Access This article is distributed under the terms of the Creative Commons Attribution 4.0 International License (http:// creativecommons.org/licenses/by/4.0/), which permits unrestricted use, distribution, and reproduction in any medium, provided you give appropriate credit to the original author(s) and the source, provide a link to the Creative Commons license, and indicate if changes were made.

\section{References}

1. Aomatsu T, Yoden A, Matsumoto K, Kimura E, Inoue K, Andoh A, Tamai H (2011) Fecal calprotectin is a useful marker for disease activity in pediatric patients with inflammatory bowel disease. Dig Dis Sci 56:2372-2377. doi:10.1007/s10620-011-1633-y

2. Belei O, Simedrea I, Ilie R, Daescu C, Tamara M, Militaru A, Brad $G$ (2011) Correlations of fecal calprotectin with clinical and endoscopic scores in inflammatory bowel diseases in children. Jurnalul Pediatrului 14(55-56):18-25

3. Bodelier A, de Boer E, Jonkers D, Hameeteman W, Masclee A, Pierik MJ (2011) Monitoring disease activity in IBD: correlation between clinical activity indices and biomarkers. Gastroenterology 140:S-423. doi:10.1016/S0016-5085(11)61737-X

4. Bremner A, Roked S, Robinson R, Phillips I, Beattie M (2007) Faecal calprotectin in children with chronic gastrointestinal symptoms. Acta Paediatr 94:1855-1858. doi:10.1111/j.1651-2227.2005. tb01870.x

5. Bross DA, Leichtner AM, Zurakowski D, Law T, Bousvaros A (1996) Elevation of serum interleukin-6 but not serum-soluble interleukin-2 receptor in children with Crohn's disease. J Pediatr Gastroenterol Nutr 23:164-171

6. Canani RB, Terrin G, Rapacciuolo L, Miele E, Siani MC, Puzone C, Cosenza L, Staiano A, Troncone R (2008) Faecal calprotectin as reliable non-invasive marker to assess the severity of mucosal inflammation in children with inflammatory bowel disease. Dig Liver Dis 40:547-553. doi:10.1016/j.dld.2008.01.017

7. D'Haens GRAM, Ferrante M, Vermeire S, Baert F, Noman M, Moortgat L, Geens P, Iwens D, Aerden I, Van Assche G, Van Olmen G, Rutgeerts P (2012) Fecal calprotectin is a surrogate marker for endoscopic lesions in inflammatory bowel disease. Inflamm Bowel Dis 18:2218-2224. doi:10.1002/ibd.22917

8 Falvey JD, Hoskin T, Meijer B, Ashcroft A, Walmsley R, Day AS, Gearry RB (2015) Disease activity assessment in IBD: clinical indices and biomarkers fail to predict endoscopic remission. Inflamm Bowel Dis 21:824-831. doi:10.1097/MIB.0000000000000341

9 Gerasimidis K, Nikolaou CK, Edwards CA, McGrogan P (2011) Serial fecal calprotectin changes in children with Crohn's disease on treatment with exclusive enteral nutrition: associations with disease activity, treatment response, and prediction of a clinical relapse. J Clin Gastroenterol 45:234-239. doi:10.1097/MCG.0b013e3181 f39af5

10 Hoekman DR, Brandse JF, de Meij TG, Hummel TZ, Löwenberg M, Benninga MA, D'Haens GR, Kindermann A (2015) The association of infliximab trough levels with disease activity in pediatric inflammatory bowel disease. Scand J Gastroenterol 50:1110-1117. doi:10.3109/00365521.2015.1027264

11 Hyams JS, Davis P, Grancher K, Lerer T, Justinich CJ, Markowitz J (1996) Clinical outcome of ulcerative colitis in children. J Pediatr 129:81-88. doi:10.1016/S0022-3476(96)70193-2

12 Kolho KL, Turner D, Veereman-Wauters G, Sladek M, de Ridder L, Shaoul R, Paerregaard A, Amil Dias J, Koletzko S, Nuti F, Bujanover Y, Staiano A, Bochenek K, Finnby L, Levine A, Veres G (2012) Rapid test for fecal calprotectin levels in children with Crohn disease. J Pediatr Gastroenterol Nutr 55:436-439. doi:10.1097/MPG.0b013e318253cffl

13 Komraus M, Wos H, Wiecek S, Kajor M, GrzybowskaChlebowczyk U (2012) Usefulness of faecal calprotectin measurement in children with various types of inflammatory bowel disease. Mediat Inflamm 2012:608249. doi:10.1155/2012/608249

14 Kopylov U, Yablecovitch D, Lahat A, Neuman S, Levhar N, Greener T, Klang E, Rozendorn N, Amitai MM, Ben-Horin S, Eliakim R (2015) Detection of small bowel mucosal healing and deep remission in patients with known small bowel Crohn's disease using biomarkers, capsule endoscopy, and imaging. Am J Gastroenterol 110:1316-1323. doi:10.1038/ajg.2015.221

15 Krzesiek E (2015) Fecal calprotectin as an activity marker of inflammatory bowel disease in children. Adv Clin Exp Med 24:815-822.

16 Levine A, Griffiths A, Markowitz J, Wilson DC, Turner D, Russell RK, Fell J, Ruemmele FM, Walters T, Sherlock M, Dubinsky M, Hyams JS (2011) Pediatric modification of the Montreal classification for inflammatory bowel disease: the Paris classification. Inflamm Bowel Dis 17:1314-1321. doi:10.1002/ibd.21493 
17 Levine A, Koletzko S, Turner D, Escher JC, Cucchiara S, de Ridder L, Kolho K-L, Veres G, Russell RK, Paerregaard A, Buderus S, Greer M-LC, Dias JA, Veereman-Wauters G, Lionetti P, Sladek M, Martin de Carpi J, Staiano A, Ruemmele FM, Wilson DC (2014) ESPGHAN revised porto criteria for the diagnosis of inflammatory bowel disease in children and adolescents. J Pediatr Gastroenterol Nutr 58:795-806. doi:10.1097/MPG.0000000000000239

18 Loonen HJ, Griffiths AM, Merkus MP, Derkx HHF (2003) A critical assessment of items on the Pediatric Crohn's Disease Activity Index. J Pediatr Gastroenterol Nutr 36:90-95

19 Modigliani R, Mary J-Y, Simon J-F, Cortot A, Soule J-C, Gendre JP, Rene E (1990) Clinical, biological, and endoscopic picture of attacks of Crohn's disease. Gastroenterology 98:811-818. doi:10.1016/0016-5085(90)90002-I

20 Mooiweer E, Severs M, Schipper MEI, Fidder HH, Siersema PD, Laheij RJF, Oldenburg B (2014) Low fecal calprotectin predicts sustained clinical remission in inflammatory bowel disease patients: a plea for deep remission. J Crohns Colitis 9:50-55. doi:10.1093 /ecco-jcc/jju003

21 Mosli MH, Zou G, Garg SK, Feagan SG, MacDonald JK, Chande N, Sandborn WJ, Feagan BG (2015) C-reactive protein, fecal calprotectin, and stool lactoferrin for detection of endoscopic activity in symptomatic inflammatory bowel disease patients: a systematic review and meta-analysis. Am J Gastroenterol 110:802-819. doi:10.1038/ajg.2015.120

22 Munkholm P, Langholz E, Nielsen OH, Kreiner S, Binder V (2009) Incidence and prevalence of Crohn's disease in the county of Copenhagen, 1962-87: a sixfold increase in incidence. Scand J Gastroenterol 27:609-614. doi:10.3109/00365529209000127

23 Nakarai A, Kato J, Hiraoka S, Inokuchi T, Takei D, Moritou Y, Akita M, Takahashi S, Hori K, Harada K, Okada H, Yamamoto K (2014) Prognosis of ulcerative colitis differs between patients with complete and partial mucosal healing, which can be predicted from the platelet count. World J Gastroenterol 20:18367-18374. doi:10.3748 /wjg.v20.i48.18367

24 Osterman MT, Aberra FN, Cross R, Liakos S, McCabe R, Shafran I, Wolf D, Hardi R, Nessel L, Brensinger C, Gilroy E, Lewis JD (2014) Mesalamine dose escalation reduces fecal calprotectin in patients with quiescent ulcerative colitis. Clin Gastroenterol Hepatol 12:1887-1893 . doi:10.1016/j.cgh.2014.03.035e3

25 Ozgenc F, Ecevit CO, Yagci RV (2012) C-reactive protein in children with active ulcerative colitis. J Pediatr 160:530 . doi:10.1016/j. jpeds.2011.11.047author reply 530-1

26 Rogler G, Biedermann L (2015) Clinical utility of biomarkers in IBD. Curr Gastroenterol Rep 17:26. doi:10.1007/s11894-015-0449-x

27 Rutgeerts P, Vermeire S, Van Assche G (2007) Mucosal healing in inflammatory bowel disease: impossible ideal or therapeutic target? Gut 56:453-455. doi:10.1136/gut.2005.088732

28 Scaioli E, Scagliarini M, Cardamone C, Liverani E, Ugolini G, Festi D, Bazzoli F, Belluzzi A (2015) Clinical application of faecal calprotectin in ulcerative colitis patients. Eur J Gastroenterol Hepatol 27:1418-1424. doi:10.1097/MEG.0000000000000461

29 Schoepfer AM, Beglinger C, Straumann A, Trummler M, Renzulli P, Seibold F (2009) Ulcerative colitis: correlation of the Rachmilewitz endoscopic activity index with fecal calprotectin, clinical activity, C-reactive protein, and blood leukocytes. Inflamm Bowel Dis 15:1851-1858. doi:10.1002/ibd.20986
30 Schoepfer AM, Beglinger C, Straumann A, Trummler M, Vavricka SR, Bruegger LE, Seibold F (2010) Fecal calprotectin correlates more closely with the Simple Endoscopic Score for Crohn's Disease (SES-CD) than CRP, blood leukocytes, and the CDAI. Am J Gastroenterol 105:162-169. doi:10.1038/ajg.2009.545

31 Shah SC, Colombel J-F, Sands BE, Narula N (2015) Systematic review with meta-analysis: mucosal healing is associated with improved long-term outcomes in Crohn's disease. Aliment Pharmacol Ther 43:317-333. doi:10.1111/apt.13475

32 Shah SC, Colombel J-F, Sands BE, Narula N (2016) Mucosal healing is associated with improved long-term outcomes of patients with ulcerative colitis: a systematic review and meta-analysis. Clin Gastroenterol Hepatol. doi:10.1016/j.cgh.2016.01.015

33 Shaoul R, Sladek M, Turner D, Paeregaard A, Veres G, Wauters GV, Escher J, Dias JA, Lionetti P, Staino A, Kolho KL, de Ridder L, Nuti F, Cucchiara S, Sheva O, Levine A (2012) Limitations of fecal calprotectin at diagnosis in untreated pediatric Crohn's disease. Inflamm Bowel Dis 18:1493-1497. doi:10.1002/ibd.21875

34 Shepanski MA, Markowitz JE, Mamula P, Hurd LB, Baldassano RN (2004) Is an abbreviated Pediatric Crohn's Disease Activity Index better than the original? J Pediatr Gastroenterol Nutr 39:68-72

35 Sipponen T, Kolho K-L (2010) Faecal calprotectin in children with clinically quiescent inflammatory bowel disease. Scand J Gastroenterol 45:872-877. doi:10.3109/00365521003782389

36 Sipponen T, Savilahti E, Kolho K-L, Nuutinen H, Turunen U, Färkkilä M (2008) Crohn's disease activity assessed by fecal calprotectin and lactoferrin: correlation with Crohn's disease activity index and endoscopic findings. Inflamm Bowel Dis 14:40-46. doi:10.1002/ibd.20312

37 Turner D, Otley AR, Mack D, Hyams J, de Bruijne J, Uusoue K, Walters TD, Zachos M, Mamula P, Beaton DE, Steinhart AH, Griffiths AM (2007) Development, validation, and evaluation of a pediatric ulcerative colitis activity index: a prospective multicenter study. Gastroenterology 133:423-432. doi:10.1053/j. gastro.2007.05.029

38 Vermeire S, Van Assche G, Rutgeerts P (2006) Laboratory markers in IBD: useful, magic, or unnecessary toys? Gut 55:426-431. doi:10.1136/gut.2005.069476

39 Voiosu T, Benguș A, Dinu R, Voiosu AM, Bălănescu P, Băicuș C, Diculescu M, Voiosu R, Mateescu B (2014) Rapid fecal calprotectin level assessment and the SIBDQ score can accurately detect active mucosal inflammation in IBD patients in clinical remission: a prospective study. J Gastrointestin Liver Dis 23:273-278

40 Wiernicka A, Szymanska S, Cielecka-Kuszyk J, Dadalski M, Kierkus J (2015) Histological healing after infliximab induction therapy in children with ulcerative colitis. World J Gastroenterol 21:10654-10661. doi:10.3748/wjg.v21.i37.10654

41 Yamaguchi S, Takeuchi Y, Arai K, Fukuda K, Kuroki Y, Asonuma K, Takahashi H, Saruta M, Yoshida H (2015) Fecal calprotectin is a clinically relevant biomarker of mucosal healing in patients with quiescent ulcerative colitis. J Gastroenterol Hepatol 31:93-98. doi:10.1111/jgh.13061

42 Yoo S, Jung YS, Park JH, Kim HJ, Cho YK, Sohn C II, Jeon WK, Kim BI, Park D II (2014) Fatigue severity and factors associated with high fatigue levels in Korean patients with inflammatory bowel disease. Gut Liver 8:148-153. doi:10.5009/gnl.2014.8.2.148 